JPPIPA, Vol.2 No.2 2017
Jurnal Penelitian Pendidikan IPA
htt//journal.unesa.ac.id/index.php/jppipa

\title{
PENGARUH PENERAPAN MODEL PEMBELAJARAN KOOPERATIF TIPE NHT DENGAN PENDEKATAN SPICES CONTINUING TERHADAP KETERAMPILAN BERPIKIR KRITIS DAN HASIL BELAJAR SISWA SMP
}

Oleh:

Hendra Eka Nurdyanto ${ }^{1}$, Sifak Indana ${ }^{2}$, Rudiana Agustini ${ }^{3}$

${ }^{1,2,3}$ Pendidikan Sains, Pascasarjana, Universitas Negeri Surabaya, Surabaya 60231, Indonesia.

${ }^{1}$ SMP Negeri 6 Mojokerto, Mojokerto 61354, Indonesia.

\begin{abstract}
Abstrak
Telah dilakukan penelitian tentang pengaruh penerapan model pembelajaran kooperatif tipe NHT dengan pendekatan SPICES Continuing terhadap keterampilan berpikir kritis dan hasil belajar siswa pada materi pembelajaran struktur lapisan bumi dan dinamikanya. Metode penelitian yang digunakan adalah quasi eksperiment. Sampel penelitan adalah siswa kelas VII SMP Negeri 6 Mojokerto yang terdiri atas kelas VII-2 sebagai kelas kontrol $(\mathrm{n}=30)$ dan kelas VII-1 sebagai kelas eksperimen $(\mathrm{n}=$ 30). Teknik pengumpulan data menggunakan teknik tes dan angket. Analisis statistik menggunakan uji anava satu jalur. Hasil penelitian menunjukkan bahwa (1) Penerapan model pembelajaran kooperatif tipe NHT dengan pendekatan SPICES Continuing berpengaruh terhadap keterampilan berpikir kritis siswa yang belajar materi struktur lapisan bumi dan dinamikanya (2) Penerapan model pembelajaran kooperatif tipe NHT dengan pendekatan SPICES Continuing berpengaruh terhadap hasil belajar antara siswa yang belajar materi struktur lapisan bumi dan dinamikanya.
\end{abstract}

Kata Kunci : model kooperatif tipe NHT, pendekatan SPICES Continuing, keterampilan berpikir kritis, hasil belajar.

\begin{abstract}
Research on the effect of NHT type cooperative learning model implementation with SPICES Continuing approach to critical thinking skill and student learning outcomes in learning materials of earth layer structure and dynamics. The research method used is quasi experiment. The research sample is the students of class VII of SMPN 6 Mojokerto consisting of class VII-2 as control class $(n=30)$ and class VII-1 as experiment class $(n=30)$. Data collection techniques used test and questionnaire techniques. Statistical analysis using one path anava test. The result of the research shows that (1) The application of NHT type cooperative learning model with SPICES Continuing approach influences the critical thinking skill of students who learn the material of earth layer structure and its dynamics (2) The implementation of NHT type cooperative learning model with SPICES Continuing approach influences the learning outcomes among students who studied the layers of earth's structural material and its dynamics.
\end{abstract}

Keywords: critical thinking skills, learning outcomes, NHT type cooperative model, SPICES Continuing approach.

(C) 2017 Universitas Negeri Surabaya

${ }^{1}$ Alamat Korespondensi:

Pendidikan Sains, Pascasarjana, Universitas

p-ISSN: $2527-7537$

Negeri Surabaya, Surabaya 60231, Indonesia.

e-ISSN: 2549-2209

Email: hendranurdyanto@mhs.unesa.ac.id 


\section{PENDAHULUAN}

Dalam era globalisasi dewasa ini tantangan peningkatan mutu dalam berbagai aspek kehidupan tidak dapat ditawar lagi. Pesatnya perkembangan IPTEKS dan era globalisasi yang menghapuskan tapal batas antarnegara, mempersyaratkan setiap bangsa untuk mengerahkan pikiran dan seluruh potensi sumber daya yang dimilikinya untuk bisa survive dan bahkan exel dalam perebutan pemanfaatan kesempatan dalam berbagai sisi kehidupan. Ini berarti perlu adanya peningkatan sikap kompetitif secara sistematik dan berkelanjutan sumber daya manusia melalui pendidikan dan pelatihan. Oleh karena itu, pendidikan dewasa ini harus diarahkan pada peningkatan daya saing bangsa agar mampu berkompetisi dalam persaingan global. Hal ini bisa tercapai jika pendidikan di sekolah diarahkan tidak semata-mata pada penguasaan dan pemahaman konsep-konsep ilmiah, tetapi juga peningkatan kemampuan dan keterampilan berpikir siswa dalam bentuk keterampilan berpikir tingkat tinggi, dengan ini dapat berupa keterampilan berpikir kritis (critical thinking skills) dan keterampilan berpikir kreatif (Creative thinking skill).

Kecakapan berpikir merupakan kemampuan yang harus dipelajari di sekolah. John Dewey, 1916 (dalam Johnson, 2002) sejak awal mengharapkan agar siswa di sekolah diajarkan cara berpikir. Kurikulum 2013 menuntut aktivasi dan partisipasi siswa yang lebih banyak dalam proses pembelajaran sehingga dapat mengasah kecakapan berpikir (thinking skill).

Kecakapan berpikir sangat penting dipelajari siswa mulai dari pendidikan dasar yaitu untuk tingkat SMP. Kecakapan berpikir di sekolah saat ini khususnya di SMP belum ditangani dengan baik. Guru hanya berupaya meningkatkan kemampuan kognitif siswa saja. Akibatnya kecakapan berpikir siswa SMP masih relatif rendah. Untuk mengajarkan kemampuan berpikir kritis di SMP khususnya dalam mata pelajaran IPA dengan struktur lapisan bumi dan dinamikanya sangat perlu dikembangkan dengan model maupun strategi pembelajaran yang sesuai. Salah satu model pembelajaran yang dapat membantu siswa untuk aktif dan melatih kemampuan berpikir kritis dan meningkatkan hasil belajarnya adalah model pembelajaran kooperatif tipe NHT dengan pendekatan SPICES Continuing.

Model pembelajaran kooperatif merupakan suatu model pembelajaran yang dapat meningkatkan pencapaian akademik dan sikap sosial peserta didik melalui kerja sama di antara siswa. Model pembelajaran kooperatif bertujuan dalam peningkatan pencapaian akademik, peningkatan rasa toleransi, dan menghargai perbedaan, serta membangun keterampilan sosial peserta didik (Arends, 2008). Kerja sama yang dilakukan oleh peserta didik dalam pelaksanaan model pembelajaran kooperatif menitikberatkan pada rasa tanggung jawab pribadi untuk pencapaian kelompok. Kurikulum 2013 mengharapkan agar manusia Indonesia memilki kemampuan hidup sebagai pribadi dan warga Negara yang beriman, produktif, kreatif, inovatif, dan efektif serta mampu berkontribusi pada kehidupan bermasyarakat, berbangsa, bernegara, dan peradaban dunia. Pembelajaran kooperatif tipe NHT merupakan salah satu tipe pembelajaran kooperatif yang menekankan pada struktur khusus yang dirancang untuk memengaruhi pola interaksi siswa dan memiliki tujuan untuk meningkatkan penguasaan akademik. Tipe ini dikembangkan oleh Kagan dalam Ibrahim (2000) dengan melibatkan para siswa dalam menelaah bahan yang tercakup dalam suatu pelajaran dan mengecek pemahaman mereka terhadap isi pelajaran tersebut.

Menurut Model SPICES hybrid curricula, inovasi bila terjadi perubahan perilaku guru atau perubahan paradigma dari karakteristik atau paradigma pembelajaran pada tataran mikro di kelas, kondisi sekarang yang ditandai dengan Teacher centered, Subject based, Dicipline-based, Hospital-based, Standadized, Opportunistic, Pregraduate, harus berangsur-angsur diubah ke arah model SPICES, yaitu Student centered, Problem-based, Integrated, Community oriented, Electives, Systematic, Continuing. Pada strategi pembelajaran inovatif guru tradisional dan peran siswa diubah, tanggungjawab siswa untuk belajar harus ditingkatkan, memberi mereka motivasi dan arahan untuk menyelesaikan program belajarnya dan menempatkan mereka pada pola tertentu agar mereka sukses sebagai pebelajar sepanjang hayat. Pada pembelajaran yang inovatif itu maka guru akan berperan sebagai sumber belajar, tutor, evaluator, pembimbing, dan memberi dukungan dalam belajar siswa (Ibrahim, 2012).

Kebanyakan pembelajaran yang menggunakan model kooperatif dapat memiliki ciri-ciri sebagai berikut (Arends, 2008):

a. Siswa bekerja dalam kelompok secara kooperatif untuk menuntaskan materi belajarnya.

b. Kelompok dibentuk dari siswa yang memiliki kemampuan tinggi, sedang, dan rendah.

c. Bilamana mungkin, anggota kelompok berasal dari ras, budaya, suku, dan jenis kelamin yang berbeda.

d. Penghargaan lebih berorientasi kelompok dari pada individu.

Hal ini sesuai dengan langkah-langkah yang terdapat pada pembelajaran kooperatif tipe NHT, yaitu guru membimbing kelompok bekerja dan belajar dalam memecahkan masalah. Langkahlangkah pembelajaran kooperatif tipe NHT ini dapat dimodifikasi dengan tahapan pendekatan SPICES Continuing sebagai berikut.

Tabel 1. Modifikasi Langkah-langkah Pembelajaran Kooperatif Tipe NHT dengan pendekatan SPICES 


\begin{tabular}{|c|c|}
\hline Tahap-tahap & Uraian Kegiatan Pembelajaran \\
\hline Kegiatan Awal & $\begin{array}{l}\text { Memotivasi siswa } \\
\text { Menyampaikan tujuan pembelajaran }\end{array}$ \\
\hline Kegiatan Inti & $\begin{array}{l}\text { a. Menyampaikan langkah-langkah NHT } \\
\text { b. Membagi siswa dalam kelompok belajar (community based), membagi LKS } \\
\text { c. Meminta siswa memperhatikan ilustrsi kasus tentang materi pembelajaran serta meminta siswa } \\
\text { mengerjakan/memecahkan masalah (problem based) pada LKS sehingga siswa berperan aktif } \\
\text { dalam pembelajaran (Student centered) } \\
\text { d. Membimbing siswa mengerjakan LKS secara terpadu (integrated) serta memberikan bantuan } \\
\text { kepada kelompok yang menemui kesulitan (Electives) } \\
\text { e. Memanggil salah satu nomor tertentu dari salah satu kelompok untuk menjawab pertanyaan yang } \\
\text { diajukan guru untuk dipresentasikan pada seluruh kelas } \\
\text { f. Memberikan kesempatan kepada kelompok lain yang bernomor sama untuk memberikan } \\
\text { tanggapan } \\
\text { g. Memberikan penghargaan kepada kelompok terbaik }\end{array}$ \\
\hline Kegiatan akhir & $\begin{array}{l}\text { a. Memberikan umpan balik } \\
\text { b. Bersama-sama membuat rangkuman materi yang telah dipelajari berdasarkan tujuan, materi dan } \\
\text { tahapan-tahapan yang jelas, logis dan tertib (systematic). }\end{array}$ \\
\hline
\end{tabular}

Menurut Kagan dalam Nur (2008) keunggulan dari pembelajaran kooperatif tipe NHT antara lain sebagai berikut:

1. Pengetahuan diperoleh siswa dengan membangun sendiri pengetahuan tersebut melalui interaksi dengan teman-temannya. Dengan demikian diharapkan pengetahuan yang diperolehnya akan lebih bermakna dan tidak sekedar hafalan semata.

2. Siswa mudah memahami materi pelajaran atau mudah menyelesaikan tugas karena menggunakan bahasa teman sebaya melalui belajar secara berkelompok.

3. Semua siswa memiliki tanggung jawab dan peluang yang sama untuk memecahkan suatu pertanyaan/masalah jika sewaktu-waktu guru menunjuk nomor secara acak untuk meminta siswa menjawab pertanyaan tersebut, dengan demikian siswa diharapkan lebih aktif dalam kegiatan pembelajaran.

4. Dapat meningkatkan rasa kerjasama, saling menghargai, serta saling membantu antar siswa dalam kelompoknya sehingga memupuk rasa sosial yang tinggi.

Berpikir kritis adalah proses mental untuk menganalisis atau mengevaluasi informasi. Informasi tersebut dapat didapatkan dari hasil pengamatan, pengalaman, akal sehat atau komunikasi. Menurut Halpen menyatakan bahwa berpikir kritis adalah memberdayakan keterampilan atau strategi kognitif dalam menentukan tujuan. Proses tersebut dilalui setelah menentukan tujuan, mempertimbangkan, dan mengacu langsung kepada sasaran-merupakan bentuk berpikir yang perlu dikembangkan dalam rangka memecahkan masalah, merumuskan kesimpulan, mengumpulkan berbagai kemungkinan, dan membuat keputusan ketika menggunakan semua keterampilan tersebut secara efektif dalam konteks dan tipe yang tepat. Berpikir kritis juga merupakan kegiatan mengevaluasi- mempertimbangkan kesimpulan yang akan diambil manakala menentukan beberapa faktor pendukung untuk membuat keputusan. Berpikir kritis juga biasa disebut directed thinking, sebab berpikir langsung kepada fokus yang akan dituju (Achmad, 2007).

Anggelo mengatakan bahwa berpikir kritis adalah mengaplikasikan rasional, kegiatan berpikir yang tinggi, yang meliputi kegiatan menganalisis, mensintesis, mengenal permasalahan dan pemecahannya, menyimpulkan, dan mengevaluasi (Achmad, 2007).

Menurut Qing berpikir kritis didefinisikan sebagai proses berpikir, yaitu bahwa individu dituntut berpikir, dan membuat evaluasi pribadi dari penilaian setelah mempelajari pengetahuan yang nyata, akurasi, proses, teori, metode, latar belakang, argumen, dan kemudian membuat akal pengambilan keputusan tentang apa yang dilakukan dan apa yang di percaya (Eswantini, 2014).

Menurut Ennis (1996), berpikir kritis memiliki lima bagian:

a. Memberikan penjelasan sederhana, yang berisi: memfokuskan pertanyaan, menganalisis pertanyaan dan bertanya, serta menjawab pertanyaan tentang suatu penjelasan atau pernyataan.

b. Membangun keterampilan dasar, yang terdiri atas mempertimbangkan apakah sumber dapat dipercaya atau tidak dan mengamati serta mempertimbangkan suatu laporan hasil observasi.

c. Menyimpulkan, yang terdiri atas kegiatan mendeduksi atau mempertimbangkan hasil deduksi, meninduksi atau mempertimbangkan hasil induksi, dan membuat serta menentukan nilai pertimbangan. 
d. Memberikan penjelasan lanjut, yang terdiri atas mengidentifikasi istilah-istilah dan definisi pertimbangan dan juga dimensi, serta mengidentifikasi asumsi.

e. Mengatur strategi dan teknik, yang terdiri atas menentukan tindakan dan berinteraksi dengan orang lain.

Berkaitan dengan pembelajaran IPA, kemampuan berpikir kritis merupakan salah satu faktor dari diri siswa (faktor internal) yang akan berpengaruh pada kelancaran dan keberhasilan proses kegiatan belajar mengajar. Menurut Widyaningrum (2014) kemampuan berpikir kritis dalam belajar IPA sangat diperlukan karena belajar IPA merupakan belajar berpikir, belajar mengorganisasi dan belajar membuktikan dengan logika. Selain itu belajar IPA juga harus sistematis, terurut dan teratur dari suatu materi ke materi yang lain, dari yang konkrit ke yang abstrak, atau dari yang mudah ke yang sukar (Winarsih dkk, 2008).

Dalam penelitian ini, peneliti ingin mengetahui apakah ada perbedaan antara keterampilan berpikir kritis dan hasil belajar siswa melalui penerapan model pembelajaran kooperatif tipe NHT dengan pendekatan SPICES Continuing dan pembelajaran konvensional yang diterapkan pada materi struktur lapisan bumi dan dinamikanya siswa kelas VII SMP Negeri 6 Mojokerto.

Aspek kemampuan berpikir kritis yang digunakan dalam penelitian ini menurut indikator Ennis yaitu menyimpulkan, yang terdiri atas kegiatan mendeduksi atau mempertimbangkan hasil deduksi, menginduksi atau mempertimbangkan hasil induksi, dan membuat serta menentukan nilai pertimbangan. Aspek hasil belajar siswa terkait penguasaan konsep struktur lapisan bumi dan dinamikanya, yaitu dinamika atmosfer, litosfer, dan hidrosfer.

\section{METODE}

Metode penelitian yang digunakan pada penelitian ini adalah penelitian kuasi eksperimental dengan desain nonequivalent control group design (Sugiyono, 2013). Desain nonequivalent control group design dalam penelitian ini melibatkan satu perlakuan dengan model pembelajaran kooperatif tipe NHT dengan pendekatan SPICES Continuing atau kelas eksperimen (X) dan satu kelas kontrol (C) dengan pembelajaran konvensional. Secara garis besar desain penelitian yang digunakan disajikan pada Tabel 2.

Tabel 2 Desain nonequivalent control group design

\begin{tabular}{cccc}
\hline Kelas & Pre-test & Perlakuan & Post-test \\
\hline Eksperimen & T1 & X & T2 \\
\hline Kontrol & T1 & C & T2 \\
\hline
\end{tabular}

Keterangan :

$\mathrm{X}=$ perlakuan dengan model pembelajaran kooperatif tipe NHT dengan pendekatan SPICES Continuing

$\mathrm{C}=$ kontrol dengan pembelajaran konvensional

$\mathrm{T} 1=$ uji awal (pre test)

$\mathrm{T} 2=$ uji akhir hasil belajar (post test)

Penelitian ini mulai dilaksanakan pada $6 \mathrm{Mei}$ 2017 sampai dengan 20 Mei 2017. Penelitian dilakukan di kelas VII-1 dan VII-2 SMPN 6 Mojokerto tahun pelajaran 2016/2017, yang beralamat di Jalan Pendidikan No.39 Kota Mojokerto. Populasi pada penelitian ini adalah siswa kelas VII SMPN 6 Mojokerto tahun pelajaran 2016/2017 yang terdiri dari 2 kelas dengan jumlah 60 orang, dari jumlah tersebut terdapat 24 siswa laki-laki dan 36 siswa perempuan.

Pengambilan sampel dilakukan secara purposive sampling dengan pertimbangan bahwa kedua kelompok memiliki kemampuan dan memiliki tingkatan usia yang relatif sama. Penelitian ini melibatkan satu variabel bebas dan satu variabel terikat. Variabel bebas adalah model

\section{HASIL DAN PEMBAHASAN}

pembelajaran, yang terdiri atas dua jenis pembelajaran, yakni (1) model pembelajaran Kooperatif Tipe NHT dengan pendekatan SPICES Continuing, dan (2) model pembelajaran konvensional. Variabel terikatnya adalah kemampuan berpikir kritis dan hasil belajar siswa. Teknik pengumpulan data yang digunakan adalah teknik tes dan nontes. Teknik tes dilakukan dengan memberikan serangkaian soal kepada siswa dalam bentuk tes objektif dan soal uraian. Teknik non tes dilakukan dengan mengumpulkan dokumendokumen berupa melaksanakan observasi. Data dianalisis secara deskriptif dan analisis statistik anava satu jalur.

\section{Keterampilan Berpikir Kritis Siswa}

Berdasarkan hasil penelitian diperoleh beberapa data yaitu data keterampilan berpikir 
kritis dan hasil belajar siswa. Data berpikir kritis dan hasil belajar siswa diperoleh melalui 2 tahapan yaitu melalui tes awal (pre-test) dan tes akhir (post test) yang dilaksanakan pada kelas eksperimen dan kelas kontrol. Data yang diperoleh yang diperoleh dari pre-test dan post-test dapat dilihat pada Tabel 3 berikut.

Tabel 3. Nilai pre-test dan post-test keterampilan berpikir kritis

\begin{tabular}{cccccc}
\hline Interval Nilai & \multirow{2}{*}{ Kategori } & \multicolumn{2}{c}{ Kelas Eksperimen } & \multicolumn{2}{c}{ Kelas Kontrol } \\
\cline { 2 - 6 } & & Pre-test & Post-test & Pre-test & Post-test \\
\hline $95-100$ & Sangat baik & - & 7 & - & 1 \\
\hline $85-94$ & Baik & - & 21 & - & 8 \\
\hline $75-84$ & Cukup & - & 2 & - & 6 \\
\hline $62-74$ & Kurang & - & - & 30 & - \\
\hline$<62$ & Sangat kurang & 30 & - & & \\
\hline
\end{tabular}

Pada tabel 3 di atas, diketahui bahwa setelah proses pembelajaran baik di kelas eksperimen maupun kelas kontrol terjadi peningkatan. Peningkatan yang lebih besar terjadi pada kelas eksperimen yang sebagian besar berada pada kategori baik dan sangat baik keterampilan berpikir kritisnya.

Tabel 4. Hasil uji normalitas data pre-test dan post-test keterampilan berpikir kritis Kelas

\begin{tabular}{cccccc}
\hline & Kelas & $\mathbf{N}$ & $\mathbf{L}_{\mathbf{0}}$ & Ltabel & Keterangan \\
\hline \multirow{2}{*}{ Pre test } & Eksperimen & 30 & 0,159 & 0,161 & Normal \\
\cline { 2 - 5 } & Kontrol & 30 & 0,126 & 0,161 & Normal \\
\hline \multirow{2}{*}{ Post test } & Eksperimen & 30 & 0,155 & 0,161 & Normal \\
\cline { 2 - 5 } & Kontrol & 30 & 0,132 & 0,161 & Normal \\
\hline
\end{tabular}

Tabel 5. Hasil uji homogenitas pre-test dan post test keterampilan berpikir kritis Kelas

\begin{tabular}{|c|c|c|c|c|c|c|c|c|}
\hline & Kelas & $\mathbf{N}$ & $\bar{x}$ & SD & $\mathrm{SD}^{2}$ & F hitung & $\begin{array}{c}\text { Ftabel } \\
(\alpha=0,05)\end{array}$ & Kesimpulan \\
\hline \multirow{2}{*}{ Pre test } & Eksperimen & 30 & 9,313 & 3,938 & 14,938 & \multirow{2}{*}{1,067} & \multirow{2}{*}{1,85} & \multirow{2}{*}{ Homogen } \\
\hline & Kontrol & 30 & 11,875 & 7,813 & 15,938 & & & \\
\hline \multirow{2}{*}{ Post test } & Eksperimen & 30 & 101,093 & 5,080 & 25,810 & \multirow{2}{*}{1,76} & \multirow{2}{*}{1,85} & \multirow{2}{*}{ Homogen } \\
\hline & Kontrol & 30 & 85,9375 & 6,742 & 45,466 & & & \\
\hline
\end{tabular}

Tabel 6. Hasil uji anava satu jalur data pre-test dan post test keterampilan berpikir kritis

\begin{tabular}{|c|c|c|c|c|c|c|c|}
\hline & Sumber & $\mathbf{J k}$ & Db & $\mathbf{R k}$ & $\mathbf{F}_{\text {hitung }}$ & $\mathbf{F}_{\text {tabel }}$ & Interpretasi \\
\hline \multirow{2}{*}{ Pre test } & Antar kelompok & 0,02 & 1 & 0,02 & \multirow{2}{*}{0,58} & \multirow{2}{*}{4,02} & \multirow{2}{*}{$\begin{array}{l}\text { Tidak ada } \\
\text { perbedaan }\end{array}$} \\
\hline & Dalam kelompok & 26,4 & 58 & 0,45 & & & \\
\hline \multirow{2}{*}{ Post test } & Antar kelompok & 156,8 & 1 & 156,8 & \multirow{2}{*}{48,90} & \multirow{2}{*}{$4, .02$} & \multirow{2}{*}{ Ada perbedaan } \\
\hline & Dalam kelompok & 186 & 58 & 3,2 & & & \\
\hline
\end{tabular}

Dengan demikian, kedua kelas yang digunakan sebagai sampel penelitian sudah berdistribusi normal dan homogen. Hal ini merupakan syarat untuk dilanjutkan ke uji anava satu jalur.

Hasil uji anava satu jalur untuk mengetahui perbedaan keterampilan berpikir kritis antara kelompok aksperimen dan kelompok kontrol dapat dilihat pada tabel 6 .

Hasil uji anava satu jalur pada Tabel 6 menunjukkan bahwa Fhitung < Ftabel $(0,58<4,02)$ sehingga hasil pre-test keterampilan berpikir kritis antara kedua kelas tidak berbeda signifikan, artinya tidak terdapat perbedaan kemampuan awal (pretest) yang signifikan antara kedua kelas. Hasil post test menunjukkan ada perbedaan keterampilan berpikir kritis antara kedua kelas tersebut, ditunjukkan bahwa Fhitung > Ftabel $(48,90<4,02)$ dimana kelas eksperimen (Kooperatif Tipe NHT dengan pendekatan SPICES Continuing) terjadi peningkatan keterampilan berpikir kritisnya lebih tinggi dibandingkan kelas kontrol (model konvensional).

Hal ini sejalan dengan pendapat Slavin (2011) bahwa penggunaan model pembelajaran kooperatif tipe NHT dapat memberikan kesempatan kepada siswa untuk menggunakan keterampilan bertanya dan membahas suatu masalah dan dapat memberikan kesempatan kepada siswa untuk lebih intensif mengadakan penyelidikan mengenai suatu masalah dengan mengunakan kemampuan 
berpikirnya. (Slavin, 2011). Demikian pula menurut Ibrahim (2012) bahwa sesuai dengan pendekatan SPICES Continuing, yaitu Student centered mengandung pengertian pembelajaran menerapkan strategi pedagogi; Problem-based yaitu pembelajaran hendaknya dimulai dari masalah-masalah aktual, otentik, relevan, dan bermakna bagi siswa; Integrated yaitu seseorang yang belajar tidak hanya tahu secara mendalam disiplin ilmunya tapi sama sekali buta tentang kaitan ilmu yang dipelajari dengan disiplin lain; Community oriented untuk mengajak siswa untuk mengimplementasikan apa yang dipelajari di dalam ke konteks masyarakat atau sebaliknya, Electives bahwa pembelajaran harus menyediakan alternatif yang dipilih oleh siswa; Systematic yaitu pembelajaran harus dilakukan secara sistematik, Continuing bahwa konsep yang diperoleh pada pembelajaran sebelumnya harus dirangkai secara kontinu dengan konsep baru yang diperoleh sehingga membentuk jalinan konsep di dalam benak seseorang.

\section{Penguasaan Konsep Struktur Lapisan Bumi Dan Dinamikanya}

Data hasil penguasaan konsep kelas eksperimen dan kelas kontrol dapat dilihat pada Tabel 7. Hasil uji normalitas data pre-test dan post test penguasaan konsep siswa dapat dilihat pada Tabel 8a dan 8 b menunjukkan bahwa kedua kelas yang digunakan berdistribusi normal. Hasil perhitungan uji homogenitas data penguasaan konsep antara kelas eksperimen dan kelas kontrol dapat dilihat pada Tabel 8a dan 8b menunjukkan bahwa kedua kelas yang digunakan homogen. Dengan demikian dapat dilakukan uji anava satu jalur untuk mengetahui apakah ada perbedaan keterampilan berpikir kritis dan hasil belajar siswa dari kelas eksperimen dan kelas kontrol.

Hasil uji anava satu jalur terhadap data penguasaan konsep antara kelas kontrol dan kelas eksperimen dapat dilihat pada Tabel 9.

Hasil uji anava satu jalur pada Tabel 9 menunjukkan bahwa Fhitung <Ftabel sehingga hasil pre-test penguasaan konsep antara kedua kelas tidak berbeda signifikan, artinya tidak terdapat perbedaan kemampuan awal (pre-test) yang signifikan antara kedua kelas. Hasil post test menunjukkan bahwa Fhitung > Ftabel (8,692 > $4,02)$, artinya terdapat perbedaan penguasaan konsep antara siswa yang belajar menggunakan model Kooperatif Tipe NHT dengan pendekatan SPICES Continuing dengan siswa yang belajar menggunakan model konvensional.

Adapun diagram persentase data penguasaan konsep antara kedua kelas dapat dilihat pada Gambar 1 dan Gambar 2.

Tabel 7. Penguasaan konsep siswa kelas eksperimen dan kelas kontrol

\begin{tabular}{cccccc}
\hline \multirow{2}{*}{$\begin{array}{c}\text { Interval } \\
\text { Nilai }\end{array}$} & Kategori & \multicolumn{2}{c}{ Kelas Eksperimen } & \multicolumn{2}{c}{ Kelas Kontrol } \\
\cline { 3 - 6 } & & Pre test & Post test & Pre test & Post test \\
\hline $100 \%$ & Istimewa & - & - & - & - \\
\hline $76 \%-99 \%$ & Baik sekali/Optimal & 1 & 18 & 2 & 11 \\
\hline $60 \%-75 \%$ & Baik/Minimal & 22 & 12 & 21 & 17 \\
\hline$<60 \%$ & Kurang & 7 & - & 9 & 2 \\
\hline
\end{tabular}

Tabel 8a. Hasil uji normalitas data pre-test dan post test penguasaan konsep

\begin{tabular}{cccccc}
\hline & Kelas & $\mathbf{N}$ & $\mathbf{L}_{\mathbf{0}}$ & $\mathbf{L}_{\text {tabel }}$ & Keterangan \\
\hline \multirow{2}{*}{ Pre test } & Eksperimen & 30 & 0,112 & 0,161 & Normal \\
\cline { 2 - 5 } & Kontrol & 30 & 0,115 & 0,161 & Normal \\
\hline \multirow{2}{*}{ Post test } & Eksperimen & 30 & 0,137 & 0,161 & Normal \\
\cline { 2 - 5 } & Kontrol & 30 & 0,144 & 0,161 & Normal \\
\hline
\end{tabular}

Tabel 8b. Hasil uji homogenitas pre-test dan post test penguasaan konsep

\begin{tabular}{|c|c|c|c|c|c|c|c|c|}
\hline & Kelas & $\mathbf{N}$ & $\overline{\mathbf{X}}$ & SD & SD2 & $\mathbf{F}_{\text {hitung }}$ & $\begin{array}{c}\mathbf{F}_{\text {tabel }} \\
(\alpha=\mathbf{0 , 0 5})\end{array}$ & Kesimpulan \\
\hline \multirow{2}{*}{ Pre test } & Eksperimen & 30 & 12,669 & 9,76751 & 95,404 & \multirow{2}{*}{1,052} & \multirow{2}{*}{1,85} & \multirow{2}{*}{ Homogen } \\
\hline & Kontrol & 30 & 12,8 & 10,01291 & 100,261 & & & \\
\hline Post test & Eksperimen & 30 & 15,88 & 8,586 & 73,679 & 1,189 & 1,85 & Homogen \\
\hline
\end{tabular}






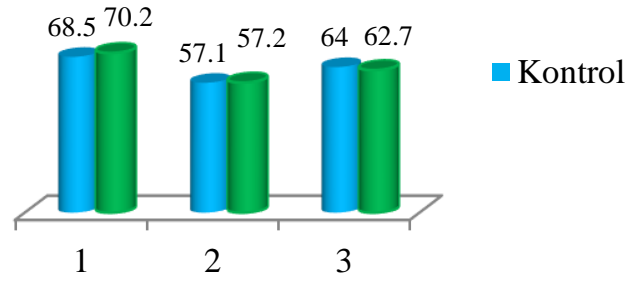

Gambar 1. Hasil Pre-Test Penguasaan Konsep

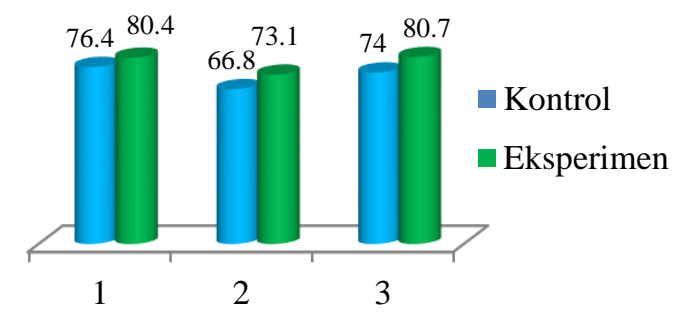

Gambar 2. Hasil Post-Test Penguasaan Konsep

Keterangan:

$1=$ Konsep atmosfer dan dinamikanya

$2=$ Konsep litosfer dan dinamikanya

(gempa bumi dan gunung api).

$3=$ Konsep hidrosfer dan dinamikanya

Gambar 1 menunjukkan penguasaan konsep kelas eksperimen dan kelas kontrol tidak berbeda secara signifikan, hal ini terbukti dari uji anava satu jalur kedua kelompok tersebut tidak ada perbedaan. Gambar 2 menunjukkan adanya perbedaan yang signifikan penguasaan konsep antara kelas eksperimen dan kelas kontrol, terbukti hasil uji anava satu jalur kedua kelompok tersebut berbeda secara signifikan, dimana pembelajaran dengan menggunakan kooperatif tipe NHT dengan pendekatan SPICES Continuing memberikan peningkatan yang cukup berarti bagi keterampilan berpikir kritis siswa dan juga hasil belajar konsep struktur lapisan bumi dan dinamikanya.

\section{SIMPULAN DAN SARAN}

\section{Simpulan}

Berdasarkan hasil disimpulkan sebagai berikut.

a. Terdapat perbedaan keterampilan berpikir kritis antara siswa yang belajar materi struktur lapisan bumi dan dinamikanya menggunakan model pembelajaran kooperatif tipe NHT dengan pendekatan SPICES Continuing dengan siswa yang belajar materi struktur lapisan bumi dan dinamikanya menggunakan pembelajaran konvensional.

b. Terdapat perbedaan penguasaan konsep antara siswa yang belajar materi struktur lapisan bumi dan dinamikanya menggunakan model pembelajaran kooperatif tipe NHT dengan pendekatan SPICES Continuing dengan siswa yang belajar materi struktur lapisan bumi dan dinamikanya menggunakan pembelajaran konvensional.

\section{Saran}

Berdasarkan hasil penelitian dapat dikemukakan beberapa saran:

a. Guru diharapkan menggunakan model kooperatif tipe NHT dengan pendekatan SPICES Continuing yang melibatkan keaktifan dan dapat mengembangkan kemampuan berpikir siswa dalam proses pembelajaran, yang salah satunya yaitu kooperatif tipe NHT dengan pendekatan SPICES Continuing.

b. Bagi guru yang akan menerapkan model kooperatif tipe NHT dengan pendekatan SPICES Continuing dalam kegiatan pembelajaran, sebaiknya mengatur waktu dengan tepat sehingga tidak mengganggu jam pembelajaran berikutnya.

c. Diharapkan agar guru memilih model yang sesuai untuk meningkatkan keterampilan berpikir kritis dan penguasaan konsep siswa.

\section{DAFTAR PUSTAKA}

Achmad, A. 2007. Memahami Berpikir Kritis. http://www. Re-searchengines.com/. (Diakses tanggal 11 November 2012). 
Arends. R.I. (2008). Learning to Teach (Belajar untuk mengajar). Yogyakarta:Pustaka Belajar.

Arikunto, S. (2008). Dasar-Dasar Evaluasi Pendidikan (Edisi Revisi). Jakarta:Bumi Aksara.

Berwald, Juli. (2007). Focus on Life Science Grade 7. Ohio: McGraw Hill Companies CCSSO.

Ennis, R. H. (1996).Critical Thinking An Instroduction. Cambride University Press.

Eswantini. (2014). "Pengembangan perangkat pembelajaran IPS model kooperatif tipe NHT untuk melatihkan berpikir kritis siswa SMP”. Tesis Magister Pendidikan. Tidak dipublikasikan. Universitas Negeri Surabaya.

Ibrahim, Muslimin. (2012). Dasar-Dasar Proses Belajar Mengajar. Surabaya: University Press

Ibrahim, Muslimin. (2000). Pembelajaran Kooperatif. Surabaya: University Press

Jihad, A \& Abdul.H. (2008). Evaluasi Pembelajaran. Yogyakarta:Multi Pressindo.

Kagan, (2009). Kagan Cooperative Learning. Kagan Publishing, San Clemente.

Kardi, S. (2012). Pengantar Pengembangan Kurikulum dan Rencana Pelaksanaan Pembelajaran. Surabaya: PPS UNESA.

Nur M, (2008). Pengajaran Berpusat Pada siswa dan Pendekatan Kontruktivisme dalam Pengajaran. PSMS Unesa.
Slavin, R.E., (2011). Psikologi Pendidikan Teori dan Praktek, Edisi kesembilan Jilid 1 diterjemahkan oleh Samosir, M. USA: Pearson.

Sudijono, A. (2010). Pengantar Evaluasi Pendidikan. Jakarta:Raja Grafindo Persada.

Sugiyono. (2013). Statistik untuk Penelitian. Bandung: Alfabeta.

Sukmadinata, N.S. (2005). Metode Penelitian Pendidikan. Bandung: PT. Remaja Rosdakarya.

Tjasyono, Bayong. (2009). Ilmu Kebumian dan antariksa. UPI, Bandung.

Widyaningrum. (2014). " Analisis kemampuan berpikir kritis siswa kelas VIII A SMP Negeri 1 Rengel-Tuban dalam pembelajaran IPA terpadu model kooperatif tipe Numbered Head Together (NHT) pada materi bunyi dan telinga". Tesis Magister Pendidikan. Tidak dipublikasikan. Universitas Negeri Surabaya.

Wilujeng, Insih. (2011). Diktat Ilmu Bumi Dan Antariksa, Yogyakarta: FMIPA Universitas Negeri Yogyakarta.

Winarsih, Nugroho, dkk. (2008). IPA Terpadu untuk SMP/MTs kelas VII. Jakarta:BSE.

Winkel, WS. (2012). Psikologi Pengajaran. Yogyakarta:Media Abadi. 